\title{
Chip-based visual detection of microRNA using DNA-functionalized gold nanoparticles
}

\author{
Ping Wang ${ }^{1,2}$, Jianlong Zhao ${ }^{1}$, Bin $\mathrm{Hu}^{3}$, Zule Cheng ${ }^{2,4}$, Yanan $\mathrm{Bai}^{2,4}$, Qinghui Jin², \\ Huiying $\mathrm{Liu}^{5}$, Hongju $\mathrm{Mao}^{2 *}$, Sanqiang $\mathrm{Li}^{1 \dagger} \&$ Jianlong $\mathrm{Zhao}^{2 \ddagger}$ \\ ${ }^{1}$ The Molecular Medicine Key Laboratory of Liver Injury and Repair, Medical College, Henan University of Science and Technology, Luoyang \\ 471003, China; \\ ${ }^{2}$ State Key Laboratory of Transducer Technology, Shanghai Institute of Microsystem and Information Technology, Chinese Academy of Sci- \\ ences, Shanghai 200050, China; \\ ${ }^{3}$ Clinical Research Center of Biological Sensing Technology, Shanghai Xuhui Central Hospital, Shanghai 200040, China; \\ ${ }^{4}$ University of Chinese Academy of Sciences, Beijing 100039, China; \\ ${ }^{5}$ Department of Oral and Maxillofacial, School of Stomatology, Dalian Medical University, Dalian 116023, China
}

Received September 23, 2015; accepted October 23, 2015; published online January 15, 2016

\begin{abstract}
In the present study, we developed a highly sensitive and convenient biosensor consisting of gold nanoparticle (AuNP) probes and a gene chip to detect microRNAs (miRNAs). Specific oligonucleotides were attached to the glass surface as capture probes for the target miRNAs, which were then detected via hybridization to the AuNP probes. The signal was amplified via the reduction of $\mathrm{HAuCl}_{4}$ by $\mathrm{H}_{2} \mathrm{O}_{2}$. The use of a single AuNP probe detected $10 \mathrm{pmol} \mathrm{L}-1$ of target miRNA. The recovery rate for miR-126 from fetal bovine serum was $81.5 \%-109.1 \%$. The biosensor detection of miR-126 in total RNA extracted from lung cancer tissues was consistent with the quantitative PCR (qPCR) results. The use of two AuNP probes further improved the detection sensitivity such that even 1 fmol L $\mathrm{L}^{-1}$ of target miR-125a-5p was detectable. This assay takes less than $1 \mathrm{~h}$ to complete and the results can be observed by the naked eye. The platform simultaneously detected lung cancer related miR-126 and miR-125a-5p. Therefore, this low cost, rapid, and convenient technology could be used for ultrasensitive and robust visual miRNA detection.
\end{abstract}

microRNA, gold nanoparticles, chip, biosensor, visual detection

Citation: $\quad$ Wang, P., Zhao, J., Hu, B., Cheng Z., Bai, Y., Jin Q., Liu, H., Mao, H., Li, S., and Zhao, J. (2016). Chip-based visual detection of microRNA using DNA-functionalized gold nanoparticles. Sci China Life Sci 59, 510-515. doi: 10.1007/s11427-015-4987-0

\section{INTRODUCTION}

MicroRNAs (miRNAs) are endogenous, highly conversed, noncoding small (21-25 nucleotides in length) RNAs. They can pair with the $3^{\prime}$ untranslated regions of mRNAs to regulate gene expression (Ambros, 2004; Bartel, 2004; Takakura et al., 2008). The change of the expression levels of miRNAs is related to various diseases, especially to cancers. Detecting miRNAs is important in the early diagnosis

*Corresponding author (email: hjmao@mail.sim.ac.cn) $\dagger$ Corresponding author (email: sanqiangli2001@163.com) †Corresponding author (email: jlzhao@mail.sim.ac.cn) of diseases as well as finding new drug targets. However, due to their short length, low abundance, and high sequence similarity, studies on miRNAs is challenging (Duan et al., 2013; Koshiol et al., 2010; Leshkowitz et al., 2013; Yang et al., 2009). Northern blotting is the most commonly used method to detect miRNAs (Cissell and Deo, 2009; Streit et al., 2008); however, it has the disadvantages of low sensitivity, complex, and time consuming, thereby limiting its utility in a clinical setting. Real-time PCR can cover a broad dynamic range with high sensitivity, but it requires precise temperature control and the short length of miRNAs makes 
the primer design very difficult (Duan et al., 2013; Git et al., 2010; Kroh et al., 2010; Ren et al., 2013). Electrochemical based methods have high sensitivity (Gao and Peng, 2011; Gao and Yu, 2007; Wen et al., 2012; Yin et al., 2012). Unfortunately, it is very difficult to detect multiple targets simultaneously. Thus, it is necessary to develop a new method for the detection of miRNAs with high sensitivity, easy operation, and low cost.

In conventional microarray technology, a fluorescentlabeled probe is usually used (Amundson et al., 1999; Schena et al., 1996; Shalon et al., 1996). Microarrays require expensive equipment and an experienced operator to read and analyze the hybridization signal, which limit their application (Wang et al., 2010). The emergence of nanomaterials provides new opportunities in biomedical research and clinical applications (Alivisatos, 2004; Cao, 2008). For example, gold nanoparticles (AuNPs) possess unique properties that enable their application in biodetection, such as size- and shape-dependent optical and electronic features, high surface area to volume ratio, good biocompatibility, and surfaces that can be modified with ligands (Giljohann et al., 2010). Oligonucleotide-modified AuNP probes combined with DNA array have been used to detect DNA (Storhoff et al., 2004; Taton et al., 2000), which has greater sensitivity than fluorophore systems. Similarly, AuNP probes and Raman-active dyes have been used to detect target nucleic acids (Cao et al., 2002). The Raman tag can be used as a narrow-band spectroscopic fingerprint and the detection limit is $20 \mathrm{fmol} \mathrm{L}^{-1}$. Based on these studies, the combination of AuNPs and microarray allows detection of nucleic acids with high sensitivity.

We developed a highly sensitive and convenient miRNA detection biosensor consisting of AuNP probes and a gene chip. As shown in Figure 1, amino-modified oligonucleotides (capture probes) were conjugated to aldehyde-coated glass chips via schiff bases. Then, target miRNAs, reporter probes, and AuNP probes were added to the system and allowed to conjugate to the chip via base pairing. Finally, an enhancement solution composed of $\mathrm{HAuCl}_{4}, \mathrm{H}_{2} \mathrm{O}_{2}$, and 2-(N-morpholino) ethanesulfonic acid (MES) was added. $\mathrm{H}_{2} \mathrm{O}_{2}$ reduces $\mathrm{HAuCl}_{4}$ to $\mathrm{Au}^{0}$ in the presence of MES buffer. The enhancement proceeds as an autocatalytic reaction: the AuNPs serve as nucleation sites to catalyze the reduc- tion of $\mathrm{Au}$ ions to metallic $\mathrm{Au}$, the reduction product is deposited on the chip, and the results are observed with the naked eye.

\section{RESULTS AND DISCUSSION}

\section{Characterization of AuNP probes}

The TEM image of the AuNPs is shown in Figure 2A. The AuNPs were highly uniform in size and suitable for use in the experiment. As shown in Figure 2B, the UV-vis spectrum of AuNPs solution has a plasmon absorption peak at $520 \mathrm{~nm}$. After modification with detection probes, the UV-vis spectrum of AuNP probes has a small surface plasmon shift from 520 to $525 \mathrm{~nm}$. The absorption peak position of AuNPs is correlated with particle size and the local chemical environment (Jain et al., 2006; Link and El-Sayed, 1999). The shift after modification of AuNPs with detection probes is likely due to the change in particle size. Gel electrophoresis experiments were performed to validate the conjugation of DNA onto the AuNP surface. As shown in Figure 2C, the AuNP probes (lane 4) migrated faster than bare AuNP solution (lane 3), which was expected due to the added negative charge from the DNA. These results suggest the successful conjugation of detection probes onto the AuNPs.

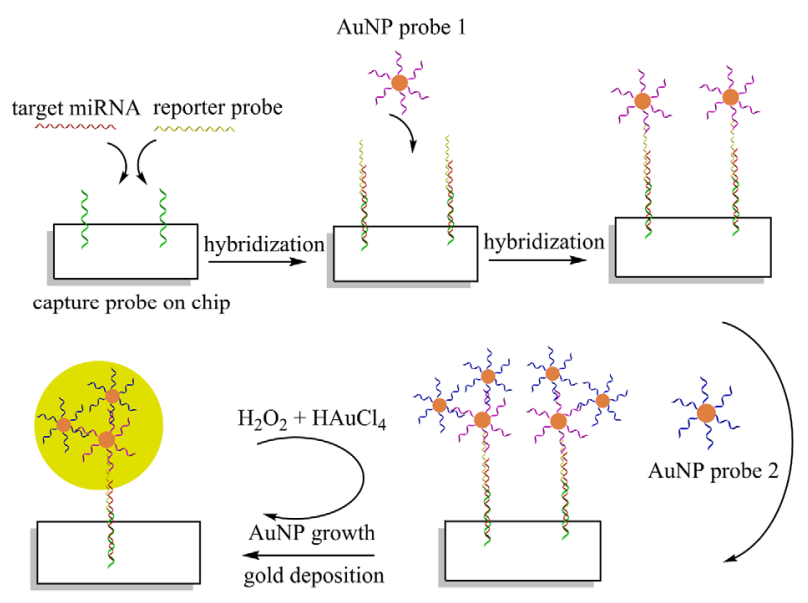

Figure 1 Schematic of miRNA detection by AuNP probes and gene chip.
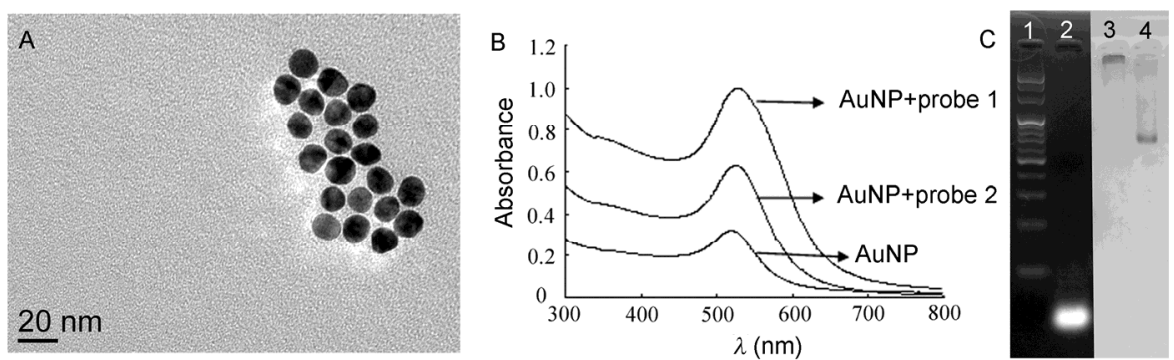

Figure 2 A, TEM image of AuNPs. B, UV-vis spectra of AuNPs solution before and after modification with DNA. C, Agarose gel (3\%) electrophoresis to validate conjugation of detection probes to AuNPs. Lane 1: 20 bp DNA ladder; lane 2: the detection probe; lane 3: AuNP solution; lane 4: AuNP probes. 
Detection of miRNAs based on a single AuNP probe and gene chip

A single AuNP probe (AuNP probe 1) was used to detect miR-125a-5p and miR-126. The concentration of the AuNP probe was estimated to be $13.4 \mathrm{nmol} \mathrm{L} \mathrm{L}^{-1}$ according to the Lambert-Beer's law. The concentration of AuNP probe 1 used was $13.4 \mathrm{nmol} \mathrm{L}^{-1}$ and the reporter probe was 100 nmol L ${ }^{-1}$. Target miRNAs at concentrations from $100 \mathrm{nmol} \mathrm{L}^{-1}$ to 10 pmol L ${ }^{-1}$ were detected (Figures 3 and 4 ). Using enhancement reaction, the gray spots were seen with the naked eye and recorded using a microscope. The signal strength was consistent with the concentration of target miRNAs (Figures 3 and 4). From the curves, the linearity range was 10 pmol $\mathrm{L}^{-1}-100 \mathrm{nmol} \mathrm{L}{ }^{-1}$ for miR-125a-5p and miR-126 $\left(R^{2}=0.999, R^{2}=0.995\right.$, respectively).

\section{Accuracy of the single AuNP probe detection system}

To evaluate the accuracy of the single AuNP probe detection system, three concentrations of standard miR-126 were added to fetal bovine serum (premixed with RNase inhibitor) and analyzed. As shown in Table 1, the recovery rate

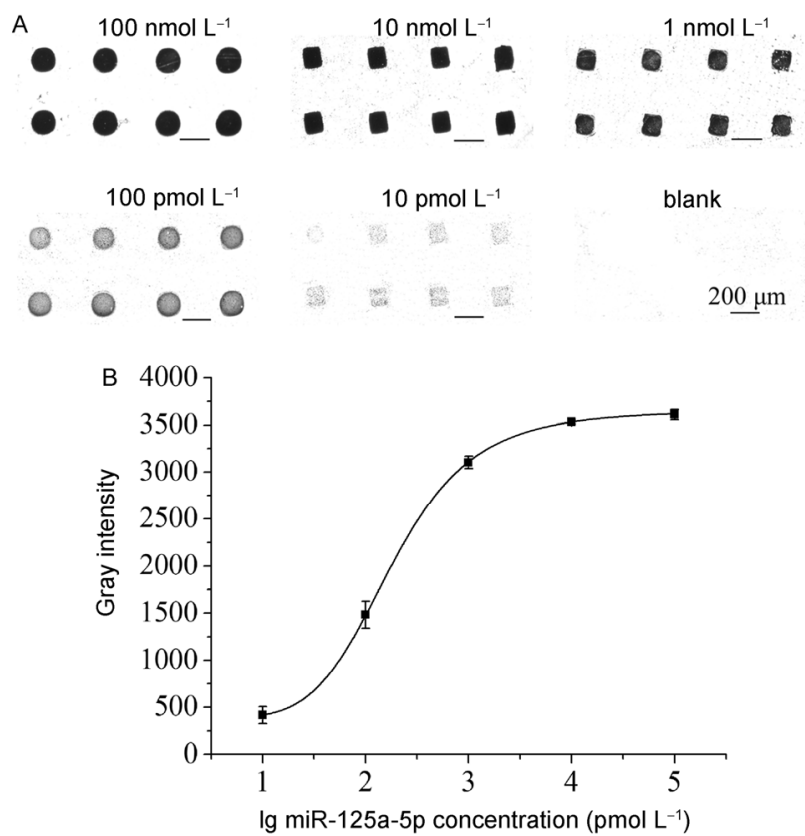

Figure 3 Detection of miR-125a-5p using a single AuNP probe and gene chip. A, A schematic of the assay in which miR-125a-5p (ranging from 100 nmol $\mathrm{L}^{-1}$ to $10 \mathrm{pmol} \mathrm{L}^{-1}$ ) and a blank control were used. $\mathrm{B}$, The relationship between gray values and the miR-125a-5p concentration. Error bars show the standard deviation of three experiments. for miR-126 was $81.5 \%-109.1 \%$, indicating the developed biosensor had good accuracy.

\section{Sample analysis}

To evaluate the practical use of our method, we used the biosensor to detect miR-126 in total RNA extract from lung cancer tissue samples collected from Shanghai Zhongshan Hospital. As shown in Table 2, the results obtained using the biosensor were consistent with that of the qPCR results and confirmed the practical use of the biosensor.

\section{Detection of miR-125a-5p based on two AuNP probes and gene chip}

\section{Probes optimization}

To further improve the detection sensitivity, we used varying concentrations of AuNP and reporter probes to detect miR-125a-5p and optimized the conditions. Firstly, the concentration of miR-125a-5p was fixed at $1 \mathrm{nmol} \mathrm{L} \mathrm{L}^{-1}$, reporter probe was $100 \mathrm{nmol} \mathrm{L}{ }^{-1}$, and AuNP probe 1 was $13.4 \mathrm{nmol} \mathrm{L}^{-1}$. AuNP probe 2 was diluted to a series of different concentrations and used for hybridization. Figure S1A

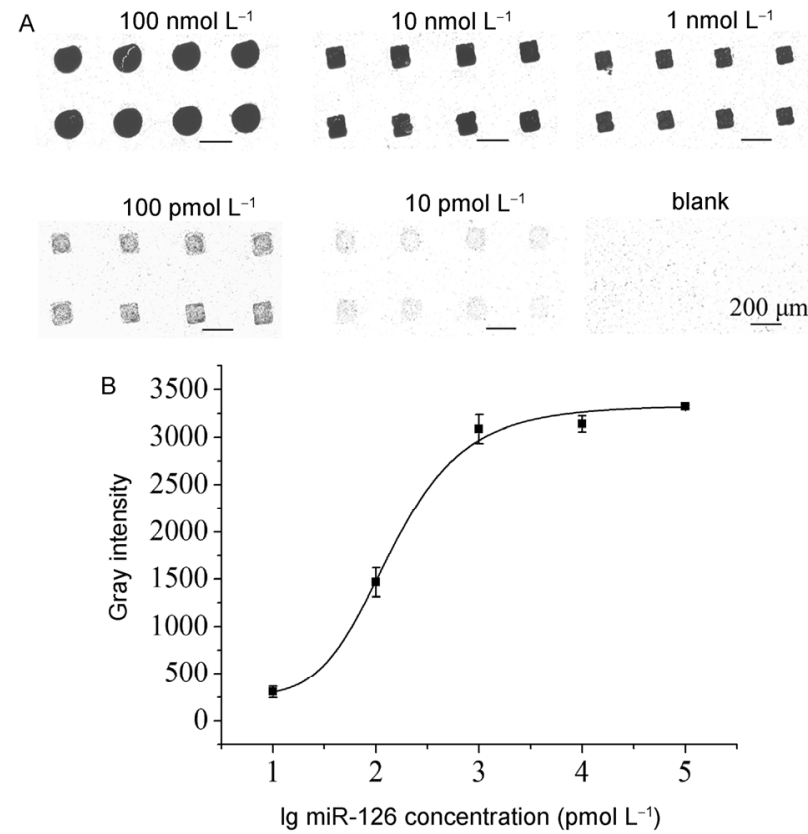

Figure 4 Detection of miR-126 using a single AuNP probe and gene chip. A, A schematic of the assay in which miR-126 (ranging from $100 \mathrm{nmol} \mathrm{L}^{-1}$ to $10 \mathrm{pmol} \mathrm{L}^{-1}$ ) and a blank control were used. $\mathrm{B}$, The relationship between gray values and the miR-126 concentration. Error bars show the standard deviation of three experiments.

Table 1 Precision of the single AuNP probe detection system

\begin{tabular}{cccc}
\hline No. & Added of miR-126 & Measurement of miR-126 & Recovery rate \\
\hline 1 & $10 \mathrm{nmol} \mathrm{L}^{-1}$ & $8.15 \mathrm{nmol} \mathrm{L}^{-1}$ & $81.5 \%$ \\
2 & $1 \mathrm{nmol} \mathrm{L}^{-1}$ & $1.091 \mathrm{nmol} \mathrm{L}^{-1}$ & $3.6 \%$ \\
3 & $100 \mathrm{pmol} \mathrm{L}^{-1}$ & $104.7 \mathrm{pmol} \mathrm{L}^{-1}$ & $109.1 \%$ \\
\hline
\end{tabular}


Table 2 Analysis of miR-126 in total RNA extracted from lung cancer tissues by our developed assay and qPCR

\begin{tabular}{ccc}
\hline No. & $\begin{array}{c}\text { Our developed assay } \\
\left(\times 10^{5} \text { copies } \mu \mathrm{L}^{-1}\right)\end{array}$ & $\begin{array}{c}\text { qPCR } \\
\left(\times 10^{5} \text { copies } \mu \mathrm{L}^{-1}\right)\end{array}$ \\
\hline 1 & $47.6 \pm 4.92$ & $35.0 \pm 1.63$ \\
2 & $5.50 \pm 1.07$ & $4.0 \pm 0.62$ \\
3 & $28.8 \pm 3.15$ & $23.2 \pm 0.80$ \\
4 & $8.32 \pm 1.24$ & $6.52 \pm 0.27$ \\
5 & $17.3 \pm 2.50$ & $10.8 \pm 0.88$ \\
6 & $47.9 \pm 3.17$ & $12.6 \pm 0.27$ \\
7 & $46.8 \pm 3.25$ & $27.5 \pm 0.35$ \\
8 & $9.12 \pm 0.71$ & $4.72 \pm 0.40$ \\
\hline
\end{tabular}

showed that the optimized concentration of AuNP probe 2 was $6.7 \mathrm{nmol} \mathrm{L}^{-1}$. Then, the concentration of AuNP probe 2 was fixed at $6.7 \mathrm{nmol} \mathrm{L}^{-1}$ and the concentration of AuNP probe 1 was optimized. Figure S1B indicates that when the AuNP probe 1 was $0.134 \mathrm{nmol} \mathrm{L}^{-1}$, the hybridization signal could reach a plateau. Finally, the concentration of reporter probe was optimized when the AuNP probe 1 and 2 were 0.134 and $6.7 \mathrm{nmol} \mathrm{L}^{-1}$, respectively. Figure $\mathrm{S} 1 \mathrm{C}$ showed the optimized concentration of reporter probe was $1 \mathrm{nmol} \mathrm{L}^{-1}$.

\section{Detection of miR-125a-5p}

We tested a series of standard miR-125a-5p concentrations (ranging from $10 \mathrm{pmol} \mathrm{L}^{-1}$ to $1 \mathrm{fmol} \mathrm{L}^{-1}$ ) with chip detection. Figure 5A showed that the gray intensity decreased as the miRNA concentration decreased. The chip detected the lowest tested concentration ( $1 \mathrm{fmol} \mathrm{L}^{-1}$ of target miRNA). Figure 5B showed the gray values were correlated with the concentration of miR-125a-5p. The linearity range was $1 \mathrm{fmol} \mathrm{L}^{-1}-10 \mathrm{pmol} \mathrm{L}-1\left(R^{2}=0.996\right)$.

\section{CONCLUSION}

We developed a novel biosensor to detect miRNAs by AuNP probes and a gene chip. The biosensor was used to detect miR-126 in lung cancer tissue samples and the results were consistent with those of qPCR, suggesting the practical use of the biosensor. Total time required was less than $1 \mathrm{~h}$ and the results are easily read by the naked eye. This assay offers a low cost, rapid, and convenient means of detecting miRNAs in clinical samples.

\section{MATERIALS AND METHODS}

\section{Reagents and apparatus}

Tetrachloroauric (III) acid trihydrate $\left(\mathrm{HAuCl}_{4} \cdot 3 \mathrm{H}_{2} \mathrm{O}\right)$ was purchased from Acros Organics (Geel, Belgium). About 2-(N-morpholino) ethanesulfonic acid (MES) was purchased from Sigma (St. Louis, USA). Gold nanoparticles (AuNPs) with diameter of $15 \mathrm{~nm}$ were purchased from

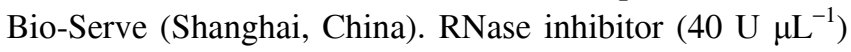
was purchased from Applied Biosystems (Foster City,

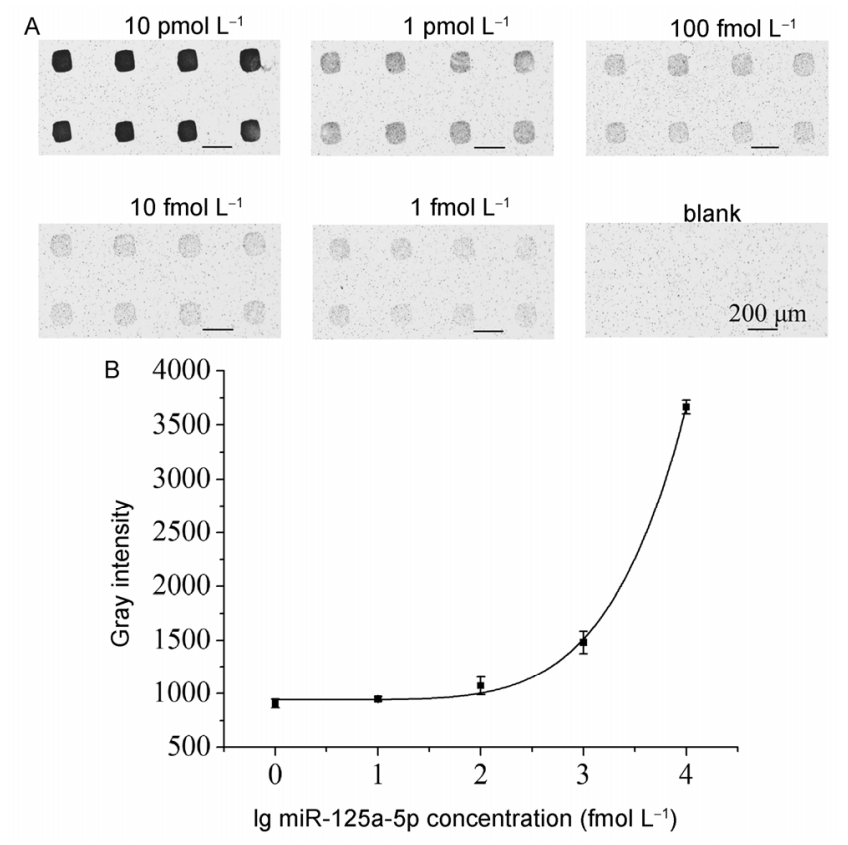

Figure 5 Detection of miR-125a-5p based on two AuNP probes and gene chip. A, A schematic of the assay in which miR-125a-5p (ranging from 10 pmol L ${ }^{-1}$ to $1 \mathrm{fmol} \mathrm{L}^{-1}$ ) and a blank control were used. B, The relationship between gray values and the miR-125a-5p concentration. Error bars show the standard deviation of three experiments.

USA). The oligonucleotides were synthesized at Takara Biotechnology, Inc. (Dalian, China) and are described in Table 3. All other reagents were of analytical grade and were used without further processing. Deionized water (resistance $>18.3 \mathrm{M} \Omega \mathrm{cm}^{-1}$ ) was used throughout the experiments.

ProSys-5510 spotting machine (Cartesian Technologies, Irvine, USA) was used to spot capture probes onto glass slides. UV-vis spectra were measured using a Jasco V-670 spectrophotometer (Tokyo, Japan). Images were recorded using an inverted microscope (model BX51; Olympus, Tokyo, Japan) with an Olympus DP-70 digital camera and DP controller software (Olympus, Tokyo, Japan).

\section{Preparation of AuNP probes}

The morphology of AuNPs was observed by transmission electron microscopy (TEM). The $\mathrm{pH}$ of AuNPs solution was adjusted to 8.2-8.5 with $0.2 \mathrm{~mol} \mathrm{~L}^{-1} \mathrm{~K}_{2} \mathrm{CO}_{3}$. After centrifuging at $8,603 \times g$ for $50 \mathrm{~min}$, the supernatant was discarded and the detection probe was added at a final concentration of $3 \mu \mathrm{mol} \mathrm{L}{ }^{-1}$ in a total volume of $100 \mu \mathrm{L}$. After storage at $4^{\circ} \mathrm{C}$ for $16 \mathrm{~h}$, phosphate buffer (PB; $0.1 \mathrm{~mol} \mathrm{~L}^{-1}, \mathrm{pH} 7.2$ ) and $\mathrm{NaCl}\left(1 \mathrm{~mol} \mathrm{~L}^{-1}\right)$ were added to the solution three times at $1 \mathrm{~h}$ intervals, and the final concentrations were 0.01 and $0.1 \mathrm{~mol} \mathrm{~L}^{-1}$, respectively. After incubating for $48 \mathrm{~h}$, the AuNP probes were isolated by centrifugation at $8,603 \times g$ for $50 \mathrm{~min}$, washed twice with $1 \mathrm{~mL}$ of the buffer $(\mathrm{pH}$ 7.2) composed of $0.01 \mathrm{~mol} \mathrm{~L}^{-1} \mathrm{~PB}$ and $0.1 \mathrm{~mol} \mathrm{~L}^{-1} \mathrm{NaCl}$. Final- 
Table 3 Sequences used in the experiment

\begin{tabular}{ll}
\hline Oligonucleotides & Sequences $\left(5^{\prime}-3^{\prime}\right)$ \\
\hline Capture probe of miR-125a-5p & $\mathrm{NH}_{2}$-TTTTTTTTTTTTTTTTTCACAGGTTAAA \\
Capture probe of miR-126 & $\mathrm{NH}_{2}$-TTTTTTTTTTTTTTTTCGCATTATTAC \\
Reporter probe of miR-125a-5p & GGGTCTCAGGGA(T) ${ }_{15}$ GTCGTCTGTTGCTCCTGTGC \\
Reporter probe of miR-126 & TCACGGTACGA(T) ${ }_{15}$ GTCGTCTGTTGCTCCTGTGC \\
Detection probe 1 & SH-TTTTTTTTTTGCACAGGAGCAACAG \\
Detection probe 2 & SH-TTTTTTTTTTCTGTTGCTCCTGTGC \\
MiR-125a-5p & UCCCUGAGACCCUUUAACCUGUGA \\
MiR-126 & UCGUACCGUGAGUAAUAAUGCG
\end{tabular}

ly, the AuNP probes were resuspended in the above buffer and stored at $4{ }^{\circ} \mathrm{C}$. The AuNP probes were characterized by the UV-vis spectra and gel electrophoresis.

\section{Preparation of gene chip}

Capture probes $\left(50 \mu \mathrm{mol} \mathrm{L}{ }^{-1}\right)$ were spotted onto the surface of the aldehyde-coated glass chips using the ProSys-5510 spotting machine. The spots contained $0.7 \mathrm{~nL}$ of each probe. The diameters of each spot were $100 \mu \mathrm{m}$, and the distance between two spots was $500 \mu \mathrm{m}$. Subsequently, the slides were kept in a moist environment at $37^{\circ} \mathrm{C}$ for two days and washed with distilled water. Then the slides were immersed in a $40 \mathrm{mmol} \mathrm{L}^{-1}$ mercaptosuccinic acid solution for $30 \mathrm{~min}$ to inactivate the remaining binding sites. Finally, the chips were washed three times with distilled water and stored at $4^{\circ} \mathrm{C}$.

\section{Preparation of the enhancement solution}

MES (25 mmol L'-1), 30\% $\mathrm{H}_{2} \mathrm{O}_{2}$, and $\mathrm{HAuCl}_{4}\left(100 \mathrm{mmol} \mathrm{L}^{-1}\right)$ were mixed in a volume ratio of $5: 3: 2$ to prepare the enhancement solution. The solution was prepared just before use in dark.

\section{RNA extraction}

Total RNA was extracted from eight frozen lung tissue samples using TRIzol reagent (Invitrogen, Carlsbad, USA) according to the manufacturer's instructions. Samples were obtained with informed consent and the study was approved by Institutional Review Board of Shanghai Zhongshan Hospital, China. The RNA quantity was evaluated by a microvolume spectrometer (Titertek-Berthold, Pforzheim, Germany).

\section{Chip-based miRNA detection}

For miRNA detection, $2 \mu \mathrm{L}$ of miRNA targets and $2 \mu \mathrm{L}$ of reporter probes were dissolved in hybridization buffer (10 mmol L ${ }^{-1}$ Tris- $\mathrm{HCl}$, pH 7.2, 1 mol L ${ }^{-1} \mathrm{NaCl}$; premixed with RNase inhibitor). The final mixture volume was $30 \mu \mathrm{L}$ for each well and was hybridized at room temperature for $30 \mathrm{~min}$ with a prepared gene chip. After hybridization, slides were washed with $0.2 \times \mathrm{SSC}(0.1 \%$ sodium dodecyl sulfate (SDS)) for $3 \mathrm{~min}$ and dried by nitrogen. Then, AuNP probes 1 and $2(2 \mu \mathrm{L}$ each) were mixed with hybridization buffer and then hybridized on the chip at room temperature for $30 \mathrm{~min}$. After washing the chip, $30 \mu \mathrm{L}$ of enhancement solution was added for each well in the dark. The staining was terminated after $5 \mathrm{~min}$ and the slides were observed under the microscope.

Compliance and ethics The author(s) declare that they have no conflict of interest.

Acknowledgements This work was supported by the National Basic Research Program of China (2012CB933303), the National Natural Science Foundation of China (61571429, 61571077, 61401442), the Innovation Team of Henan University of Science and Technology (2015XTD003), the Science and Technology Commission of Shanghai Municipality (12441902600, 1402H233900) and the Shanghai Clinical Center/Shanghai Xuhui Central Hospital, Chinese Academic of Sciences (BRC2012002).

Alivisatos, P. (2004). The use of nanocrystals in biological detection. Nat Biotechnol 22, 47-52.

Ambros, V. (2004). The functions of animal microRNAs. Nature 431, 350-355.

Amundson, S.A., Bittner, M., Chen, Y., Trent, J., Meltzer, P., and Fornace, A.J. (1999). Fluorescent cDNA microarray hybridization reveals complexity and heterogeneity of cellular genotoxic stress responses. Oncogene 18, 3666-3672.

Bartel, D.P. (2004). MicroRNAs: genomics, biogenesis, mechanism, and function. Cell 116, 281-297.

Cao, Y.C. (2008). Nanomaterials for biomedical applications. Future Med 3, 467-469.

Cao, Y.C., Jin, R., and Mirkin, C.A. (2002). Nanoparticles with raman spectroscopic fingerprints for DNA and RNA detection. Science 297, 1536-1540.

Cissell, K.A., and Deo, S.K. (2009). Trends in microRNA detection. Anal Bioanal Chem 394, 1109-1116.

Duan, R., Zuo, X., Wang, S., Quan, X., Chen, D., Chen, Z., Jiang, L., Fan, C., and Xia, F. (2013). Lab in a tube: ultrasensitive detection of microRNAs at the single-cell level and in breast cancer patients using quadratic isothermal amplification. J Am Chem Soc 135, 4604-4607.

Gao, Z., and Peng, Y. (2011). A highly sensitive and specific biosensor for ligation-and PCR-free detection of microRNAs. Biosens Bioelectron 26, 3768-3773.

Gao, Z., and Yu, Y.H. (2007). Direct labeling microRNA with an electrocatalytic moiety and its application in ultrasensitive microRNA assays. Biosens Bioelectron 22, 933-940.

Giljohann, D.A., Seferos, D.S., Daniel, W.L., Massich, M.D., Patel, P.C., and Mirkin, C.A. (2010). Gold nanoparticles for biology and medicine. Angew Chem Int Edit 49, 3280-3294.

Git, A., Dvinge, H., Salmon-Divon, M., Osborne, M., Kutter, C., Hadfield, J., Bertone, P., and Caldas, C. (2010). Systematic comparison of microarray profiling, real-time PCR, and next-generation sequencing 
technologies for measuring differential microRNA expression. RNA 16, 991-1006.

Jain, P.K., Lee, K.S., El-Sayed, I.H., and El-Sayed, M.A. (2006). Calculated absorption and scattering properties of gold nanoparticles of different size, shape, and composition: applications in biological imaging and biomedicine. J Phys Chem B 110, 7238-7248.

Koshiol, J., Wang, E., Zhao, Y., Marincola, F., and Landi, M.T. (2010). Strengths and limitations of laboratory procedures for microRNA detection. Cancer Epidem Biomar 19, 907-911.

Kroh, E.M., Parkin, R.K., Mitchell, P.S., and Tewari, M. (2010). Analysis of circulating microrna biomarkers in plasma and serum using quantitative reverse transcription-PCR (qRT-PCR). Methods 50, 298-301.

Leshkowitz, D., Horn-Saban, S., Parmet, Y., and Feldmesser, E. (2013). Differences in microRNA detection levels are technology and sequence dependent. RNA 19, 527-538.

Link, S., and El-Sayed, M.A. (1999). Size and temperature dependence of the plasmon absorption of colloidal gold nanoparticles. J Phys Chem B 103, 4212-4217.

Ren, Y., Deng, H., Shen, W., and Gao, Z. (2013). A highly sensitive and selective electrochemical biosensor for direct detection of microRNAs in serum. Anal Chem 85, 4784-4789.

Schena, M., Shalon, D., Heller, R., Chai, A., Brown, P.O., and Davis, R.W. (1996) Parallel human genome analysis: microarray-based expression monitoring of 1000 genes. Proc Natl Acad Sci USA 93, 10614-10619.

Shalon, D., Smith, S.J., and Brown, P.O. (1996). A DNA microarray system for analyzing complex DNA samples using two-color fluorescent probe hybridization. Genome Res 6, 639-645.

Storhoff, J.J., Marla, S.S., Bao, P., Hagenow, S., Mehta, H., Lucas, A.,
Garimella, V., Patno, T., Buckingham, W., Cork, W., and Müller, U.R. (2004). Gold nanoparticle-based detection of genomic DNA targets on microarrays using a novel optical detection system. Biosens Bioelectron $19,875-883$.

Streit, S., Michalski, C.W., Erkan, M., Kleeff, J., and Friess, H. (2008). Northern blot analysis for detection and quantification of RNA in pancreatic cancer cells and tissues. Nat Protoc 4, 37-43.

Takakura, S., Mitsutake, N., Nakashima, M., Namba, H., Saenko, V.A., Rogounovitch, T.I., Nakazawa, Y., Hayashi, T., Ohtsuru, A., and Yamashita, S. (2008). Oncogenic role of miR-17-92 cluster in anaplastic thyroid cancer cells. Cancer Sci 99, 1147-1154.

Taton, T.A., Mirkin, C.A., and Letsinger, R.L. (2000). Scanometric DNA array detection with nanoparticle probes. Science 289, 1757-1760.

Wang, Y., Mao, H.J., Zang, G.Q., Zhang, H.L., Jin, Q.H., and Zhao, J.L. (2010). Detection of hepatitis B virus deoxyribonucleic acid based on gold nanoparticle probe chip. Chin J Anal Chem 38, 1133-1138.

Wen, Y., Pei, H., Shen, Y., Xi, J., Lin, M., Lu, N., Shen, X., Li, J., and Fan, C. (2012). DNA nanostructure-based interfacial engineering for PCR-free ultrasensitive electrochemical analysis of microRNA. Sci Rep $2,867$.

Yang, H., Hui, A., Pampalakis, G., Soleymani, L., Liu, F.F., Sargent, E.H., and Kelley, S.O. (2009). Direct, electronic microRNA detection for the rapid determination of differential expression profiles. Angew Chem Int Edit 48, 8461-8464.

Yin, H., Zhou, Y., Zhang, H., Meng, X., and Ai, S. (2012). Electrochemical determination of microRNA-21 based on graphene, LNA integrated molecular beacon, AuNPs and biotin multifunctional bio bar codes and enzymatic assay system. Biosens Bioelectron 33, 247-253.

Open Access This article is distributed under the terms of the Creative Commons Attribution License which permits any use, distribution, and reproduction in any medium, provided the original author(s) and source are credited.

\section{SUPPORTING INFORMATION}

Figure S1 Optimization of AuNP probe 2 (A), AuNP probe 1 (B) and reporter probe (C).

The supporting information is available online at life.scichina.com and link.springer.com. The supporting materials are published as submitted, without typesetting or editing. The responsibility for scientific accuracy and content remains entirely with the authors. 